\title{
LIBERDADE E JUSTIÇA EM MARX: UMA ARGUMENTAÇÃO ÉTICA CONTRA O INDIVIDUALISMO POSSESSIVO
}

\author{
Freedom and justice in Marx: an ethical argument against possessive individualism
}

Ricardo Rojas Fabres*

Resumo: Em contraste com acusações liberais e interpretações ortodoxas do marxismo, este trabalho pretende refutar a ideia de que a relação entre Marx e a Justiça resume-se à tese de que os princípios normativos expressam apenas interesses de classe (Callinicos, 2003). Pretendemos sugerir que tanto a crítica à exploração capitalista quanto o desenho de um novo modelo de organização social expostos por Marx estão baseados em princípios de justiça (Roemer, 2008; Geras, 1985; Elster, 1994). Assim, levando em conta, entre outros aspectos, o perceptível declínio da política de classes (Fraser, 2002), rejeitamos a inevitabilidade histórica do socialismo e passamos a situar o marxismo no centro de um debate sobre diferentes orientações normativas (Cohen, 2008; 2001). Por fim, trabalhamos o conceito de emancipação humana do jovem Marx (1986; 2010), buscando debater a autonomia não como uma compreensão individualista, mas como condição para o livre desenvolvimento coletivo, a partir do múltiplo desenvolvimento das possibilidades humanas (Bottomore, 1983; Marx, 2010).

Palavras-chave: Marxismo. Justiça. Teoria Crítica.

\begin{abstract}
In contrast to liberal assumptions and Orthodox interpretations of Marxism , this study aims to refute the idea that the relationship between Marx and Justice summed up the thesis that normative principles express only class interests (Callinicos, 2003). Mean to suggest that both the critique of capitalist exploitation as the design of a new model of social organization exposed by Marx are based on principles of justice (Roemer, 2008; Geras, 1985; Elster, 1994). Thus, taking into account, inter alia, the perceived decline of class politics (Fraser, 2002), we reject the historical inevitability of socialism and we put the Marxism on the center of a debate on different normative guidelines (Cohen, 1986; 1994). Finally, we work the concept of human emancipation of the young Marx (1986, 2010), debating autonomy not as an individualistic understanding, but as a condition for the free development collective, from the multiple development of human possibilities (Bottomore, 1983; Marx, 2010).

Keywords: Marxism. Justice. Critical Theory.
\end{abstract}

* Mestrando do Programa de Pós-graduação em Filosofia da Universidade Federal de Pelotas (UFPel). Contato: ricardofabres_@hotmail.com

\begin{tabular}{|c|c|c|c|c|c|}
\hline intuitio & $\begin{array}{c}\text { ISSN } \\
1983-4012\end{array}$ & Porto Alegre & Vol.7- $\mathrm{N}^{\circ} .1$ & $\begin{array}{l}\text { Junho } \\
2014\end{array}$ & p.169-181 \\
\hline
\end{tabular}




\section{Introdução: Marx e a justiça}

Este trabalho começa a ser delineado sobre uma pergunta fundamental: "Existe uma concepção de justiça em Marx?". E esta questão, por sua vez, desdobra-se em outra não menos importante: "o capitalismo, do ponto de vista marxista, é injusto?". Antes de tentarmos responder uma ou outra, ou as duas, devemos situá-las em um longo debate que arrasta-se, no mínimo, pelos últimos cem anos. A ideia de que os escritos de Marx possuem princípios normativos de justiça encontra grande resistência dentro do marxismo, onde mostra-se aparentemente hegemônico o argumento de que princípios universais e concepções normativas expressam interesses de classe e, desta forma, contribuem para ocultar os antagonismos sociais "sob a fachada do bem-estar geral"1.

Em princípio tais argumentações encontram respaldo nos escritos de Marx, especialmente em um Marx que escreve: "os comunistas não pregam nenhuma moral"². Na prática, esta afirmação, como outras passagens presentes nos escritos do jovem Marx, demonstram uma tentativa radical de desprender-se do horizonte especulativo-idealista da filosofia alemã que o antecedeu (algo bastante claro na Critica da filosofia do direito de Hegel). Assim, a constatação se voltaria, conforme as teses centrais do materialismo histórico, à impossibilidade de buscar normas universais e imperativos categóricos, visto que a análise materialista deveria fundar-se, justamente, em uma análise rigorosamente científica e econômica das contradições do capitalismo (Quiniou, 2012). Neste sentido, Allen W. Wood, em Justice and class interests, vai mais além ao sustentar que para Marx tanto a distribuição de bens quanto a relação entre capitalista e trabalhador seriam justas, pois "se harmonizam com o modo de produção capitalista"3.

Semelhante constatação oferece o liberal Alan Ryan ao afirmar que, segundo Marx, os capitalistas estavam "encerrados dentro das mesmas relações de exploração com seus empregados, e estas tinham que ser, e eram, compatíveis com os padrões burgueses de justiça em um nível superficial, irreflexivo"4. Realmente, poderíamos interpretar, de forma preliminar embora coerente, que a possível justeza desta relação reside na compatibilidade de sua natureza moral com as condições práticas em que se baseia a situação da classe economicamente dirigente. Ou, em outras palavras, como dirá Engels no Anti-Dühring, que o conteúdo moral da relação é compatível com a moral hegemônica da sociedade. Entretanto, este não é um ponto sobre o qual poderíamos nos deter neste momento. O que podemos considerar é que um forte argumento contra a existência de princípios normativos de justiça na obra de Marx reside na compreensão explícita do autor (e de interpretações posteriores) sobre o caráter ideológico da moral. Seguindo este raciocínio, para Marx, "a moral, a

\footnotetext{
${ }^{1}$ CALLINICOS, A. "Igualdade e capitalismo". IN BORON; A, AMADEO; J, GONZÁLES, S (org.). La teoría marxista hoy. Buenos Aires: CLACSO (2006), p. 273.

${ }^{2}$ MARX, K; ENGELS, F. A ideologia alemã. Boitempo Editorial, 2007, p. 241.

${ }^{3}$ WOOD, A, "Justice and class interests". Philosophica, n 33, 1984, p. 9-32.

${ }^{4}$ RYAN, A, “Justicia, Explotacion y el fin de la Moral”. Revista de Ciência Política, XII, nº 1-2, 1990, p. 55
}

\begin{tabular}{|c|c|c|c|c|c|}
\hline intuitio & $\begin{array}{c}\text { ISSN } \\
1983-4012\end{array}$ & Porto Alegre & Vol.7- $\mathrm{N}^{\mathrm{o}} .1$ & $\begin{array}{c}\text { Junho } \\
2014\end{array}$ & p.169-181 \\
\hline
\end{tabular}


religião, a metafísica e qualquer outra ideologia", enquanto "uma superestrutura jurídica e política e à qual correspondem formas sociais determinadas de consciência" estariam sobre a base real da sociedade, isto é, sobre "a totalidade dessas relações de produção [que] constitui [sua] estrutura econômica"' .

A partir destas relações, portanto, Marx chega à coerente conclusão que

Toda nova classe que toma o lugar de outra que dominava anteriormente é obrigada para atingir seus fins, a apresentar seu interesse como o interesse comum de todos os membros da sociedade, quer dizer, expresso de forma ideal: é obrigada a dar às suas ideias a forma de universalidade, a apresentá-las como as únicas racionais, universalmente válidas ${ }^{8}$.

Assim, deste ponto de vista, poderíamos destacar três constatações: a) a moral é, para Marx, parte constitutiva de uma ideologia, como a religião, por exemplo; b) o caráter universal da moral, em verdade, representa interesses particulares de classe; c) o conteúdo da moral é definido, em primeira instância, pelas relações materiais que compõem a estrutura econômica da sociedade. Entretanto, estas ponderações não seriam suficientes para assentar uma objeção categórica em relação à presença de princípios normativos nos escritos de Marx, especialmente do jovem Marx - haja vista, por exemplo, sua dedicação em elaborar aquilo que o próprio autor considera como "o imperativo categórico de subverter todas as relações em que o homem é um ser humilhado, escravizado, abandonado, desprezível"9. Para Domenico Losurdo, esta é uma prova que "o rigor científico e a indignação moral resultam tão entrelaçados entre si [que] somente este entrelaçamento pode explicar o apelo à revolução" ${ }^{\prime 10}$.

O fato é que, longe de um consenso sobre o tema, autores como Norman Geras, Gerald Cohen, Jon Elster e Adolfo Sánchez Vázquez, dentre outros, insistem na possibilidade de se pensar uma concepção marxista da moral. Cohen e Elster, por exemplo, defendem abertamente a mudança de uma perspectiva clássica do marxismo para a filosofia normativa. No caso de Cohen, o autor concluiu que "o materialismo histórico não era determinante para a praxis emancipatória enquanto as questões normativas eram"11. Em síntese, a motivação para este giro no sentido da filosofia normativa, em Cohen, deu-se a partir da constatação de que a igualdade econômica não era historicamente inevitável e, neste sentido, a desintegração da classe trabalhadora, semelhante ao que Nancy Fraser denomina “declínio da política de classes" (Fraser, 2002; 2006), e o colapso do projeto socialista da União Soviética (Reyes Morel, 2008), que Vázquez (1993) considera como uma negação da tradição

\footnotetext{
${ }^{5}$ MARX, K; ENGELS, F. A ideologia alemã. Boitempo Editorial, 2007, p. 94.

${ }^{6}$ MARX, K, Contribuição à crítica da economia política. 2.ed.- São Paulo : Expressão Popular, 2008, p. 47.

${ }^{7}$ MARX, K, Contribuição à crítica da economia política. 2.ed.- São Paulo : Expressão Popular, 2008, p. 47.

${ }^{8}$ MARX, K; ENGELS, F. A ideologia alemã. Boitempo Editorial, 2007, p. 48.

${ }^{9}$ MARX, K, Contribuição à crítica da economia política. 2.ed.- São Paulo : Expressão Popular, 2008, p. 154.

${ }^{10}$ LOSURDO, D. Como nasceu e como morreu o marxismo ocidental. Estudos sociológicos, Araraquara, v.16, n.30, 2011, p. 213-242. Disponível em http://piwik.seer.fclar.unesp.br/estudos/article/view/3897/3578 Acessado em: 06 de Junho de 2014.

${ }^{11}$ REYES, M. El socialismo normativo de G.A. Cohen: justicia como igualdad y comunidad. Universidad de Valencia, 2008, p. 45.
}

\begin{tabular}{|c|c|l|l|l|l|}
\hline intuitio & $\begin{array}{c}\text { ISSN } \\
1983-4012\end{array}$ & Porto Alegre & Vol.7- $\mathrm{N}^{\mathrm{o}} .1$ & $\begin{array}{c}\text { Junho } \\
2014\end{array}$ & p.169-181 \\
\hline
\end{tabular}


emancipatória do marxismo, apresentavam-se como razões evidentes da necessidade de se articular uma nova perspectiva para a renovação do marxismo.

De uma forma geral, deixou-se de lado a crença determinista que apontava a revolução proletária como uma evolução natural da história, de modo que não seria mais razoável pensar no desenvolvimento das forças produtivas como único critério válido para trilhar o caminho da emancipação humana. Em que pese não se tenha abandonado completamente as teses centrais da teoria marxista, esta constatação provocou um profundo interesse na identificação e na justificação dos pré-requisitos normativos de uma sociedade igualitária ${ }^{12}$. Desta forma, o marxismo passou a ocupar espaço no centro de um debate a respeito das exigências normativas do agir humano (Cohen, 1986; 1994). Esta mudança poderia ser resumida de forma bastante simples substituindo a questão "como alcançar o socialismo?" pela questão "por que alcançar o socialismo?", sendo que a segunda opção refere-se especificamente à tentativa de demonstrar a superioridade moral do socialismo em comparação ao capitalismo - ou, em outras palavras, a superioridade de determinados princípios normativos sobre outros.

Naturalmente, considerável parte dos marxistas, aparentemente, não se negariam a admitir que Marx condenava o capitalismo. Entretanto, o que nos interessa é consolidar a sugestão de que Marx não apenas condenava o capitalismo, mas o fazia a partir de princípios de justiça. Sobre isso, Norman Geras em The Controversy about Marx and Justice concluiu que um paradoxo nos escritos de Marx seria o fato de ele estar mais compromissado com a criação de uma sociedade justa do que na análise do que é justiça. Por outro lado, o autor destaca também que seria uma interpretação espúria supor que Marx defendesse os ideais de liberdade, autorrealização e comunidade mas repudiasse a justiça ${ }^{13}$. A explicação para o primeiro paradoxo, segundo Cohen, se dá devido à crença inicial dos marxistas em relação à inevitabilidade do comunismo. De acordo com o autor,

Foi em parte porque acreditavam que a igualdade econômica era historicamente inevitável que os marxistas clássicos não dispensaram muito tempo refletindo sobre sua correção moral, sobre precisamente que princípios normativos fundamentais estabeleciam sua superioridade moral. A igualdade comunista estava a caminho, ela era bem vinda, e seria uma perda de tempo teorizar sobre porque ela era bem vinda ao invés de teorizar sobre como fazê-la chegar o mais rapidamente e da forma menos indolor que fosse possível ${ }^{14}$.

Neste sentido, Vázquez acredita que a crítica de Marx refere-se aos "valores negados no sistema social que se critica, mas próprios da sociedade alternativa que propõe para substituí-lo"15. De fato, em A questão judaica, Marx ao referir-se aos direitos humanos defendidos pelas revoluções

${ }^{12}$ BIDET, J; KOUVELAKIS, S. (ed). Critical Companion to Contemporary Marxism, Vol. 16. Brill, 2008. p. 88

${ }^{13}$ GERAS, N. "The controversy about Marx and justice". New left review, v. 150, n. 3, 1985, p. 78-79.

${ }^{14}$ COHEN, G. A. "Equality as fact and as norm: reflections on the (partial) demise of marxism." Lua Nova: Revista de Cultura e Política, $n^{o}$ 33, 1994, 123-134. p. 124. Disponível em http://www.scielo.br/scielo.php?pid=S0102-64451994000200009\&script=sci_arttext\&tlng=es Acessado em: 06 de Junho de 2014.

15 SÁNCHEZ VÁZQUEZ, Adolfo. "Después del Derrumbe: Estar o no a la izquierda." Sistema. Revista de Ciencias Sociales, n⿳0 108, 1992, p. 57-67.

\begin{tabular}{|c|c|c|c|c|c|}
\hline intuitio & $\begin{array}{c}\text { ISSN } \\
1983-4012\end{array}$ & Porto Alegre & Vol.7- $\mathrm{N}^{\mathrm{o}} .1$ & $\begin{array}{l}\text { Junho } \\
2014\end{array}$ & p.169-181 \\
\hline
\end{tabular}


burguesas afirma:

O direito humano à liberdade não se baseia na vinculação do homem com os demais homens, mas, ao contrário, na separação entre um homem e outro. Trata-se do direito a essa separação, o direito do indivíduo limitado, limitado a si mesmo ${ }^{16}$.

A crítica, não há dúvida, está clara. Entretanto, Marx vai além, transparecendo uma concepção bastante exigente de liberdade. No Manifesto Comunista, escrito em parceria com Engels, o autor afirma que o livre desenvolvimento de cada um é a condição para o livre desenvolvimento de todos ${ }^{17}$. Em A ideologia alemã, da mesma forma, Marx aponta que "somente na comunidade [com outros que cada] indivíduo tem os meios de desenvolver suas faculdades em todos os sentidos; somente na comunidade, portanto, a liberdade pessoal torna-se possível"18. E conclui: "na comunidade real, os indivíduos obtêm simultaneamente sua liberdade na e por meio de sua associação"19.

De todos os modos, ao reconstruir o que buscamos expor até aqui, não precisamos abandonar algumas teses fundamentais do materialismo histórico para concluir que as ideias morais são produtos sociais e, como tais, nas sociedades de classe seu conteúdo também é atravessado por interesses de classe. Assim, para um planejamento da crítica ao capitalismo e suas formas de dominação seria necessário que esta crítica estivesse baseada em uma espécie de "moral alternativa", isto é, um conjunto de práticas que, vistos de fora do condicionante social, poderiam se impor como moralmente superiores. Não há dúvidas, ao mesmo tempo, que esta posição levaria não apenas a um relativismo moral, mas também à abstrações impróprias, de modo que uma saída para esta possível contradição reside, justamente, no caráter real e objetivo da crítica proposta por Marx.

Em linhas gerais, o que Marx dirá é que o capitalismo está em desacordo com a sua própria ideia moral e, para isso, não é necessário recorrer a outros princípios morais, apenas demonstrar objetivamente como, de fato, isto acontece. A exploração capitalista da força de trabalho, por exemplo, ao não encerrar-se em um contrato entre as partes envolvidas, adquire um caráter social sobre o qual se ergue outros tipos de relações igualmente desiguais e que, igualmente, negam os princípios morais estabelecidos pelo capitalismo. E esta constatação fica evidente quando Marx caracteriza esta relação como "roubo", "usurpação", "escamoteio" - para utilizar os termos de O Capital. Da mesma forma, quando aponta para a construção de uma nova sociedade, a partir da superação da propriedade privada, Marx parece demonstrar a superioridade moral desta nova sociedade a partir de sua reafirmação dos valores negados pelo capitalismo.

\section{Autonomia, Dignidade e Exploração}

Do ponto de vista moral, a crítica de Marx ao modo de produção capitalista alcançará seu

${ }^{16}$ MARX, K. Sobre a questão judaica. Boitempo Editorial, 2010, p. 49.

${ }^{17}$ MARX, K, ENGELS, F. Manifesto comunista. Boitempo Editorial, 1998.

${ }^{18}$ MARX, K; ENGELS, F. A ideologia alemã. Boitempo Editorial, 2007, p. 64.

${ }^{19}$ MARX, K; ENGELS, F. A ideologia alemã. Boitempo Editorial, 2007, p. 64.

\begin{tabular}{|c|c|l|l|l|l|}
\hline intuitio & $\begin{array}{c}\text { ISSN } \\
1983-4012\end{array}$ & Porto Alegre & Vol.7- No.1 & $\begin{array}{l}\text { Junho } \\
2014\end{array}$ & p.169-181 \\
\hline
\end{tabular}


ponto central na crítica às relações de produção e à exploração capitalista. Não precisamos rejeitar as teses de Wood (1984) e Ryan (1990) para admitir que, no capitalismo, o intercâmbio de equivalentes entre capital e força de trabalho não é imoral, ou injusto, visto que está de acordo com a moral hegemônica. Entretanto, a crítica de Marx dirige-se justamente ao processo pelo qual este intercâmbio torna-se desigual, isto é, uma troca entre mais trabalho por menos trabalho que, por sua vez, gera a mais-valia (produto este gerado pelo trabalho e apropriado pelo capital). Assim, podemos sugerir que a ideia moral dominante, isto é, a moral burguesa, está em desacordo com o seu correspondente econômico: o modo de produção capitalista. Ou, em outras palavras, que o capitalismo pode ser moralmente criticado (e acreditamos que assim o foi por Marx) a partir de sua própria ideia moral.

Desta forma, em sua explicação de como se dá o processo de apropriação da força de trabalho no capitalismo, Marx oferece como chave do materialismo histórico a afirmativa que a classe dominante de cada modo de produção possui seu método particular de extrair o excedente econômico dos produtores. No caso do capitalismo, isto se dá a partir da escassez de capital em relação à oferta disponível de força de trabalho. Ao falar sobre a existência da oferta ser maior que a procura, Marx (2004) considera que uma parte dos trabalhadores "cai na situação de miséria ou na morte pela fome"20 e disto conclui: "o trabalhador tornou-se uma mercadoria e é uma sorte para ele conseguir chegar ao homem que se interesse por ele. E a procura, da qual a vida do trabalhador depende, depende do capricho do rico e capitalista" 21 .

Esta consideração refere-se a uma situação particular do capitalismo: a dependência do trabalhador em relação ao capital. Nos Manuscritos Econômico-filosóficos, Marx se debruça sobre esta questão. Segundo ele, pensando nas "três situações principais em que a sociedade pode se encontrar"22 (1 - quando a riqueza da sociedade está em declínio, 2 - quando a riqueza da sociedade está em crescimento, 3 - quando a riqueza da sociedade está em situação plena), na melhor delas (a riqueza plena) o trabalhador está em uma situação de "miséria estacionária"23. O trabalhador, portanto, ao mesmo tempo em que depende do capital para manter sua existência física e sua efetiva participação material na sociedade, vê os interesses da sociedade se contraporem aos seus.

Assim, dirá Marx, a economia nacional, termo que mais tarde será substituído por "economia política" 24 , estabelece a proposição que o trabalhador "tal como todo cavalo tem de receber o suficiente para poder trabalhar" 25 , isto é, a economia nacional "conhece o trabalhador apenas como animal de trabalho, como uma besta reduzida às mais estritas necessidades corporais" ${ }^{26}$ ao mesmo tempo em que "considera o trabalho abstratamente como uma coisa; o trabalho é uma mercadoria" 27 ,

${ }^{20}$ MARX, K. Manuscritos econômico-filosóficos. Boitempo Editorial, 2004, p. 24.

${ }^{21}$ MARX, K. Manuscritos econômico-filosóficos. Boitempo Editorial, 2004, p. 24.

${ }^{22}$ MARX, K. Manuscritos econômico-filosóficos. Boitempo Editorial, 2004, p. 25.

${ }^{23}$ MARX, K. Manuscritos econômico-filosóficos. Boitempo Editorial, 2004, p. 28.

${ }^{24}$ MARX, K. Manuscritos econômico-filosóficos. Boitempo Editorial, 2004, p. 19.

${ }^{25}$ MARX, K. Manuscritos econômico-filosóficos. Boitempo Editorial, 2004, p. 30.

${ }^{26}$ MARX, K. Manuscritos econômico-filosóficos. Boitempo Editorial, 2004, p. 32.

${ }^{27}$ MARX, K. Manuscritos econômico-filosóficos. Boitempo Editorial, 2004, p. 35.

\begin{tabular}{|c|c|l|l|l|l|}
\hline intuitio & $\begin{array}{c}\text { ISSN } \\
1983-4012\end{array}$ & Porto Alegre & Vol.7- $\mathrm{N}^{\mathrm{o}} .1$ & $\begin{array}{c}\text { Junho } \\
2014\end{array}$ & p.169-181 \\
\hline
\end{tabular}


de modo que "com a valorização do mundo das coisas aumenta em proporção direta a desvalorização do mundo dos homens" ${ }^{28}$. A denúncia de Marx em relação a um tipo de trabalho que considera o homem como uma mercadoria, "um animal de trabalho", assemelha-se ao princípio kantiano de que o homem deveria ser tratado como um fim em si mesmo.

Esta é, em suma, uma das mais importantes contribuições de Marx em seus escritos de juventude: a constatação de que a estrutura econômica do modo de produção capitalista transformou o homem em uma engrenagem da produção e reprodução da atividade capitalista, a ponto de concebê-lo como uma das mercadorias produzidas por ele. Pois bem, se na produção material o homem é reduzido a um meio, é humilhado a ponto de ser concebido como um cavalo, uma besta ou uma mercadoria, seria esta uma sociedade decente para Marx? Neste sentido, poderíamos dizer que o filósofo Avishai Margalit oferece uma contribuição importante ao diferenciar uma sociedade decente de uma sociedade civilizada, sendo a primeira aquela em que as instituições não humilham os indivíduos e a segunda aquela em que os indivíduos não se humilham entre $\mathrm{si}^{29}$.

Se pudéssemos estabelecer um diálogo entre os conceitos de Margalit e os escritos de Marx, diríamos que para este a sociedade capitalista não é decente tampouco civilizada. Assim como se dá com a escravidão, no capitalismo a exploração deriva da autoridade superior sobre a força de trabalho do produtor. A diferença, como mostra Gerald Cohen em Karl Marx's Theory of History: a defense, se dá porque na escravidão e na servidão "não há venda de força de trabalho do produtor ao explorador. A exploração se consegue mediante uma coerção extraeconômica" ${ }^{30}$. Entretanto, como no capitalismo o trabalhador assalariado é proprietário de sua força de trabalho este não pode ser ameaçado por negarse a utilizá-la, embora, por não possuir os meios de produção, vê-se obrigado "a firmar um contrato sob pena de morrer de fome" ${ }^{31}$.

A questão que parece impor-se neste ponto é a seguinte: o trabalhador, para assegurar sua existência material, isto é, seu bem mais precioso que é a vida, submete-se a um contrato pelo qual oferece força de trabalho e em troca recebe meios de subsistência. A objeção liberal (Ryan, 1990) neste caso diz respeito ao fato de que as condições estabelecidas neste contrato são justas na medida em que ambas as partes estão de acordo com suas condições. Por outro lado, podemos afirmar que esta justeza é aparente, dado que na relação efetiva o trabalhador não a escolhe a partir de suas preferências, mas em busca da sobrevivência. Callinicos resume esta relação da seguinte forma:

Um dos pressupostos básicos do capitalismo como sistema econômico é que a maioria da população não possui nenhuma alternativa aceitável à opção de vender sua força de trabalho em termos suficientemente desfavoráveis para conduzi-los a

\footnotetext{
${ }^{28}$ MARX, K. Manuscritos econômico-filosóficos. Boitempo Editorial, 2004, p. 80.

${ }^{29}$ REGO, WL; PINZANI, A, Vozes do Bolsa Família: autonomia, dinheiro e cidadania. São Paulo: Editora UMESP (2013).

${ }^{30}$ COHEN, G. A. La teoría de la historia de Karl Marx: una defensa. Madrid: Pablo Iglesias, Siglo XXI de España, 1986, p. 91.

${ }^{31}$ COHEN, G. A. La teoría de la historia de Karl Marx: una defensa. Madrid: Pablo Iglesias, Siglo XXI de España, 1986, p. 91.
}

\begin{tabular}{|c|c|l|l|l|l|}
\hline intuitio & $\begin{array}{c}\text { ISSN } \\
1983-4012\end{array}$ & Porto Alegre & Vol.7- $\mathrm{N}^{\circ} .1$ & $\begin{array}{c}\text { Junho } \\
2014\end{array}$ & p.169-181 \\
\hline
\end{tabular}


sua exploração $0^{32}$

Em que pese tenhamos que admitir a complexidade das relações de produção contemporâneas, o importante aqui, sem fugir do objetivo deste trabalho, é demonstrar se existe ou não um princípio de justiça por trás da análise de Marx sobre a exploração capitalista. Neste sentido, parece razoável supor que, para Marx, o homem perde sua dignidade duplamente: 1) quando "a procura [por trabalho], da qual a vida do trabalhador depende, depende do capricho do rico e capitalista" ${ }^{33}$, isto é, quando sua própria existência, antes de ser autônoma depende de uma vontade externa a ele e sobre a qual ele mesmo não possui qualquer gerência e 2) quando o seu ser resume-se a "um animal de trabalho", "uma besta reduzida às mais estritas necessidades corporais" ${ }^{34}$, ou seja, quando é tratado com um meio e não como um fim em si mesmo.

Esta nos parece, portanto, a motivação para que Marx conclua a necessidade de superação do trabalho alienado, isto é, a necessidade do "comunismo na condição de supra-sunção positiva da propriedade privada" 35 . Ou, em outras palavras, o que ele chama de "o imperativo categórico de subverter todas as relações em que o homem é um ser humilhado, escravizado, abandonado,

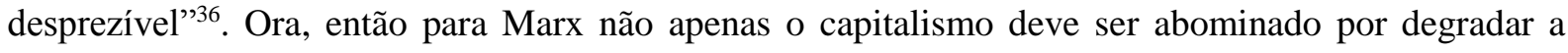
dignidade e a autonomia dos homens mas também é necessário instaurar como categórica a tarefa de organizar uma sociedade onde sejam realizados, de fato, estes princípios. Princípios, diríamos, não de classe, mas universais.

\section{Uma argumentação ética contra o individualismo possessivo}

Para Marx, A democracia política, ao conceder igualdade de direitos políticos, transforma em soberano o homem, mas o homem em sua manifestação não cultivada, o homem que não é um "ser genérico real". Ou seja, tal democracia política, onde os homens são politicamente iguais, onde as diferenças de nascimentos são consideradas diferenças não políticas, em verdade, não desfazem as desigualdades reais existentes entre os homens. Pelo contrário, reduz à abstração a existência do cidadão, submetendo-o ao indivíduo egoísta, ao bourgeoi, tornando a existência política um aparato da sociedade burguesa. Em outras palavras, como afirma Chasin (2000) em sua determinação ontonegativa da politicidade:

É muito importante notar que não se trata apenas de uma conciliação contra o princípio de universalidade, que lastreia idealmente os atos políticos, mas de uma subordinação degenerativa da política às particularidades da sociedade civil, no

${ }^{32}$ CALLINICOS, A. "Igualdade e capitalismo". IN BORON; A, AMADEO; J, GONZÁLES, S (org.). La teoría marxista hoy. Buenos Aires: CLACSO (2006), p. 273-293.

${ }^{33}$ MARX, K. Manuscritos econômico-filosóficos. Boitempo Editorial, 2004, p. 24.

${ }^{34}$ MARX, K. Manuscritos econômico-filosóficos. Boitempo Editorial, 2004, p. 32.

${ }^{35}$ MARX, K. Manuscritos econômico-filosóficos. Boitempo Editorial, 2004, p. 105.

${ }^{36}$ MARX, K. Crítica da filosofia do direito de Hegel. Boitempo Editorial, 2005. p. 152.

\begin{tabular}{|c|c|l|l|l|l|}
\hline intuitio & $\begin{array}{c}\text { ISSN } \\
1983-4012\end{array}$ & Porto Alegre & Vol.7- No.1 & $\begin{array}{l}\text { Junho } \\
2014\end{array}$ & p.169-181 \\
\hline
\end{tabular}


sentido de que a cidadania, a comunidade política são reduzidas a simples meio ${ }^{37}$

Temos aqui, finalmente, de forma bastante esclarecedora, a crítica de Marx à emancipação política enquanto "dissolução da sociedade antiga, sobre a qual está baseado o sistema estatal alienado do povo, o poder do soberano"38. "A revolução política é a revolução da sociedade burguesa", pontua Marx. Neste sentido, buscamos a pertinente interpretação de Michael Löwy sobre a crítica a emancipação política, que transforma "a vida política em um simples meio a serviço da vida civilburguesa e o homem enquanto "cidadão" num servidor do homem enquanto "burguês" 39

Entretanto, como já foi demonstrado anteriormente, Marx é taxativo a admitir o progresso representado pela emancipação política, considerando-a "a forma definitiva da emancipação humana dentro da ordem mundial vigente até aqui” ${ }^{40}$. Como afirma Bensaïd (2010),

Essa frase por si só deveria refutar a acusação de que Marx seria indiferente às "liberdades formais", aos "direitos democráticos" e à "democracia burguesa". Ele os considera como conquistas preciosas numa perspectiva histórica, como "a forma definitiva" da emancipação na ordem atual do mundo. Portanto, necessárias, mas insuficientes. O que se trata de transgredir para prolongar o movimento de emancipação rumo à sua plenitude humana são os limites desse mundo ${ }^{41}$.

Não se trata, portanto, de menosprezar a emancipação política e suas conquistas, dentre as quais destacam-se, principalmente, a consolidação dos chamados direitos civis. Se trata, por outro lado, de compreender os limites e a transitoriedade destas conquistas rumo à uma emancipação efetivamente humana. Neste sentido, a natureza individual e privada destes direitos, insinua dirá Marx, a consolidação da sociedade burguesa - do homem egoísta, individualista. Assim, o parâmetro emancipatório construído de acordo com esta sociedade representa, em última instância, os direitos do indivíduo contra o Estado e, mais ainda, representa a consolidação dos direitos não dos homens, mas de um tipo de homem - o homem burguês. Vejamos, portanto, como aponta Coutinho, a diferença em relação ao conceito grego de cidadania, para o qual, "ser cidadão não é algo que se refira à vida privada, mas precisamente à vida pública, à qual os gregos claramente subordinam a esfera privada" 42 .

Retomemos ao texto e a diferenciação que Marx faz entre os direitos humanos e direitos do cidadão, que confirma nossa constatação:

\footnotetext{
${ }^{37}$ CHASIN, J. "A determinação ontonegativa da politicidade", Ensaios Ad Hominem/ Estudos e Edições Ad Hominem; $\quad \mathrm{n}^{\mathrm{o}} \quad 1, \quad$ tomo III, 2000. p. $51 \quad$ Disponível em http://verinotio.org/Verinotio_revistas/n15/ontonegativa_politicidade.pdf Acessado em: 06 de Junho de 2014.

${ }^{38}$ CHASIN, J. "A determinação ontonegativa da politicidade", Ensaios Ad Hominem/ Estudos e Edições Ad Hominem; $\mathrm{n}^{\mathrm{o}} \quad 1$, tomo III, 2000. p. $51 \quad$ Disponível em http://verinotio.org/Verinotio_revistas/n15/ontonegativa_politicidade.pdf Acessado em: 06 de Junho de 2014.

${ }^{39}$ LÖWY, M. A teoria da revolução no jovem Marx. Petrópolis: Vozes, 2002, p. 96.

${ }^{40}$ MARX, K. Sobre a questão judaica. Boitempo Editorial, 2010, p. 41.

${ }^{41}$ BENSAÏD, D. "Apresentação: uma crítica da emancipação política. Trad: Wanda Caldeira Brant. IN: MARX, K. Sobre a questão judaica. São Paulo: Boitempo (2010), p. 87

${ }^{42}$ COUTINHO, C.N. "Cidadania e modernidade." Perspectivas: Revista de Ciências Sociais 22.1, 2009, P.45. Disponível em http://piwik.seer.fclar.unesp.br/perspectivas/article/download/2087/1709 Acessado em: 06 de Junho de 2014.
}

\begin{tabular}{|c|c|l|l|l|l|}
\hline intuitio & $\begin{array}{c}\text { ISSN } \\
1983-4012\end{array}$ & Porto Alegre & Vol.7- $\mathrm{N}^{\mathrm{o}} .1$ & $\begin{array}{c}\text { Junho } \\
2014\end{array}$ & p.169-181 \\
\hline
\end{tabular}


Quem é esse homem que é diferenciado do citoyen? Ninguém mais ninguém menos que o membro da sociedade burguesa. Por que o membro da sociedade burguesa é chamado de "homem", pura e simplesmente, e por que os seus direitos são chamados de direitos humanos? A partir de que explicaremos esse fato? A partir da relação entre o Estado político e a sociedade burguesa, a partir da essência da emancipação política ${ }^{43}$.

Ora, esta essência demonstra que o homem se liberta a partir de um horizonte estreito, que opõe sua vida genérica no Estado à sua existência concreta como membro da sociedade burguesa. Para esclarecer esta questão, Marx recorre à Constituição Francesa de 1793, "a constituição mais radical", segundo ele. A partir "dos direitos naturais e imprescritíveis", isto é, a "igualdade, a liberdade, a segurança e a propriedade" ${ }^{44}$, Marx questiona: em que consiste a liberdade? E responde, com base na própria constituição: "La liberté est le pouvoir qui appartient à l'homme de faire tout ce qui ne nuit pas aux droits d'autrui",45, ou conforme a Declaração dos direitos humanos de 1791: "La liberté consiste à pouvoir faire tout ce qui ne nuit pas à autrui ${ }^{, 46}$.

A liberdade, portanto, é o direito de não prejudicar o outro, é a realização do homem enquanto "mônada isolada recolhida dentro de si mesma" ${ }^{47}$. E disto Marx concluirá que a liberdade conquistada pelo indivíduo com a emancipação política torna-se o próprio obstáculo para a efetivação de sua liberdade, visto que o direito do homem à liberdade se baseia na separação do homem em relação ao seu semelhante. A liberdade se baseia "na separação entre um homem e outro. Trata-se do direito a essa separação, o direito do indivíduo limitado, limitado a si mesmo"48, pontua Marx. Em contraposição a isto, em A ideologia Alemã, o autor afirmaria:

Apenas na coletividade [de uns e outros] é que cada indivíduo encontra os meios de desenvolver suas capacidades em todos os sentidos; somente na coletividade, portanto, torna-se possível a liberdade pessoal ${ }^{49}$.

Para o autor, além disso, o direito humano da liberdade é a aplicação prática do direito humano à propriedade privada, quer dizer, "Le droit de propriété est celui qui appartient à tout citoyen de jouir et de disposer à son gré de ses biens, de ses revenus, du fruit de son travail et de son industrie"50. Vemos, desta forma, que Marx compreende este caráter da "liberdade individual" e sua aplicação prática como o fundamento da sociedade burguesa, sociedade esta que "faz com que cada homem veja

\footnotetext{
${ }^{43}$ MARX, K. Sobre a questão judaica. Boitempo Editorial, 2010, p. 48.

${ }^{44}$ MARX, K. Sobre a questão judaica. Boitempo Editorial, 2010, p. 48.

45 "A liberdade é o poder que pertence ao homem de fazer tudo quanto não prejudica os direitos do próximo." (N. T.). MARX, K. Sobre a questão judaica. Boitempo Editorial, 2010, p. 48.

46 "A liberdade consiste em poder fazer tudo que não prejudica a nenhum outro." (N.T.). MARX, K. Sobre a questão judaica. Boitempo Editorial, 2010, p. 48.

${ }^{47}$ MARX, K. Sobre a questão judaica. Boitempo Editorial, 2010, p. 49.

${ }^{48}$ MARX, K. Sobre a questão judaica. Boitempo Editorial, 2010, p. 49.

${ }^{49}$ MARX, K. A ideologia alemã. Boitempo Editorial, 1987, p. 116-117.

50 "O direito de propriedade é aquele que pertence a todo cidadão de gozar e dispor à vontade de seus bens, rendas, fruto de seu trabalho e de sua indústria." (N. T.). MARX, K. Sobre a questão judaica. Boitempo Editorial, 2010, p. 49.
}

\begin{tabular}{|c|c|l|l|l|l|}
\hline intuitio & $\begin{array}{c}\text { ISSN } \\
1983-4012\end{array}$ & Porto Alegre & Vol.7- $\mathrm{N}^{\mathrm{o}} .1$ & $\begin{array}{c}\text { Junho } \\
2014\end{array}$ & p.169-181 \\
\hline
\end{tabular}


no outro homem, não a realização, mas, ao contrário, a restrição de sua liberdade" ${ }^{51}$. O mesmo ocorre, segundo ele, com a igualdade, que significa que "cada homem é visto uniformemente como mônada que repousa em si mesma" 52 .

Esta concepção individualista teve como resultado uma concepção não menos individualista de autonomia, de modo que a criação de relações sociais justas deva "servir primeiramente à finalidade de possibilitar a todos os sujeitos igualmente uma forma de autodeterminação que os permita ser tão independentes de seus parceiros de interação quanto possível" ${ }^{\text {53 }}$. E, por consequência, a noção de que a sociedade é um objetivo de sujeitos individualizados e não uma característica dos próprios sujeitos fez com que se cristalizasse nas teorias contemporâneas da justiça o argumento que advoga em prol da menor intervenção possível nos projetos individuais que cada um constrói para si.

Não por acaso, muitas vezes recorreu-se à existência de um Estado de Natureza para legitimar o ordenamento social. Entretanto, como mostra Macpherson, o Estado de Natureza, na verdade, retrata "a maneira da qual os indivíduos, sendo o que são, se comportariam inevitavelmente se não houvesse nenhuma autoridade para obrigar ao cumprimento da lei ou do contrato" ${ }^{24}$. Hobbes não se referia, portanto, ao estado psicológico intrínseco à existência humana ou as características naturais dos seres humanos, tampouco se referia a organização social dos homens primitivos. Pelo contrário, mostra Macpherson,

Seu Estado de Natureza é uma afirmação quanto ao comportamento a que seriam levados os indivíduos (como são agora, indivíduos que vivem em sociedades civilizadas e que têm desejos de homens civilizados) se fosse suspensa a obrigação ao cumprimento de todas as leis e contratos [...] Para conseguir o Estado de Natureza Hobbes deixou de lado a lei, mas não o comportamento e os desejos humanos socialmente adquiridos ${ }^{55}$.

Segue o autor afirmando que o comportamento dos seres humanos descrito por Hobbes como natural, "aquele para o qual eles são inevitavelmente levados pelas suas paixões" ${ }^{56}$, pode ser visto no comportamento de seres civilizados. Isto é, a dedução oriunda das paixões, em verdade refere-se às paixões dos seres civilizados. Assim, quando Hobbes refere-se aos homens que "no caminho para seu fim esforçam-se por se destruir ou subjugar um ao outro", que estão prontos para desapossar e privar o outro "não apenas do fruto de seu trabalho, mas também de sua vida e de sua liberdade", os homens que "não tiram prazer algum da companhia uns dos outros", o autor não se refere a outro homem

${ }^{51}$ MARX, K. Sobre a questão judaica. Boitempo Editorial, 2010, p. 49.

52 MARX, K. Sobre a questão judaica. Boitempo Editorial, 2010, p. 49

${ }^{53}$ HONNETH, A. "A textura da justiça Sobre os limites do procedimentalismo contemporâneo." Civitas-Revista $\begin{array}{llllll}\text { de } & \text { Ciências } & \text { Sociais } & 9.3 & 2009 . & \text { Disponível }\end{array}$ http://revistaseletronicas.pucrs.br/ojs/index.php/civitas/article/view/6896/5023 Acessado em: 06 de Junho de 2014.

${ }^{54}$ MACPHERSON, C.B. A teoria política do individualismo possessivo, de Hobbes até Locke. Paz e Terra, 1979, p. 30.

${ }_{55}$ MACPHERSON, C.B. A teoria política do individualismo possessivo, de Hobbes até Locke. Paz e Terra, 1979, p. 33.

${ }^{56}$ MACPHERSON, C.B. A teoria política do individualismo possessivo, de Hobbes até Locke. Paz e Terra, 1979, p. 34.

\begin{tabular}{|c|c|c|c|c|c|}
\hline intuitio & $\begin{array}{c}\text { ISSN } \\
1983-4012\end{array}$ & Porto Alegre & Vol.7- No.1 & $\begin{array}{l}\text { Junho } \\
2014\end{array}$ & p.169-181 \\
\hline
\end{tabular}


senão o homem civilizado destituído de instituições políticas.

Como mostra Anderson (1984), estas tradições teóricas possuem uma concepção reacionária da natureza humana, uma natureza "invariavelmente agressiva e, ao mesmo tempo, conservadora, individualista, mas inerte - uma permanente advertência contra experiências radicais e transformações revolucionárias" ${ }^{57}$. De acordo com o autor,

A esquerda sempre combateu essas ideias de uma natureza humana eterna e incontrolável, em nome da variabilidade social dos seres humanos, sob ordens históricas diversas, e sua perfectibilidade sob condições que os emancipem, ao invés de oprimi-los ${ }^{58}$.

Isto nos leva à necessidade de uma abordagem materialista da história, capaz de refutar um Estado de Natureza como subterfúgio de legitimação das estruturas sociais. Neste sentido, a crítica de Marx refere-se ao liberalismo e seu correspondente jurídico e filosófico, que garantem a "subordinação degenerativa da política às particularidades da sociedade civil" ${ }^{2}$, especialmente os chamados "direitos do homem", que legitimam o homem egoísta, o homem burguês, considerando-o como uma "mônada isolada", "cujo único vínculo de unidade é o interesse privado"60.

\section{Considerações Finais}

Até aqui, se admitirmos a razoabilidade de nossa argumentação, podemos supor que a crítica de Marx baseia-se em um conjunto de princípios morais proclamados pelo próprio capitalismo quando de sua ascensão enquanto modo de produção hegemônico. Dirá Marx que o homem não pode ser escravizado e esta constatação está plenamente de acordo com o que afirma Kant - que atuar livremente é atuar autonomamente. E se Kant diz que o homem deve ser tratado "sempre como um fim e nunca apenas como um meio", Marx, sem dúvida, não negaria. O que Marx demonstra, por meio de uma rigorosa análise, é que o capitalismo não oferece as condições concretas para que estes princípios (liberdade, igualdade e dignidade, por exemplo) se manifestem de fato, dado que sua realização econômica se funda na negação da liberdade plena, da dignidade humana e da igualdade de oportunidades - fazendo da exploração uma forma de instrumentalização do indivíduo.

Procuramos sustentar, portanto, que a crítica marxista ao capitalismo contém, na essência, um conteúdo ético, embora não se restrinja à ele: não apenas porque o capitalismo reduz as liberdades individuais ao plano formal, mas também porque este sistema não consegue oferecer nem as circunstâncias necessárias para os indivíduos alcançarem uma boa vida, tampouco para que vivam nas condições humanas indispensáveis. Vale destacar, inclusive, que neste debate específico o propósito

\footnotetext{
${ }^{57}$ ANDERSON, P. "A crise da crise do marxismo." São Paulo: Brasiliense, 1984, p. 94.

${ }^{58}$ ANDERSON, P. "A crise da crise do marxismo." São Paulo: Brasiliense, 1984, p. 94.

${ }^{59}$ CHASIN, J. "A determinação ontonegativa da politicidade", Ensaios Ad Hominem/ Estudos e Edições Ad Hominem; $\mathrm{n}^{\mathrm{o}}$ 1, tomo III, 2000.

${ }^{60}$ LÖWY, M. A teoria da revolução no jovem Marx. Petrópolis: Vozes, 2002.
}

\begin{tabular}{|c|c|c|c|c|c|}
\hline intuitio & $\begin{array}{c}\text { ISSN } \\
1983-4012\end{array}$ & Porto Alegre & Vol.7- No.1 & $\begin{array}{c}\text { Junho } \\
2014\end{array}$ & p.169-181 \\
\hline
\end{tabular}


deste trabalho abraça considerável interesse pela ideia de que, embora a justiça distributiva não seja capaz de dissolver em toda a sua magnitude as injustiças provenientes das relações capitalistas, ainda assim deixa em aberto possibilidades para uma construção teórica crítica orientada para a emancipação.

\section{Referências}

ANDERSON, P. A crise da crise do marxismo. São Paulo: Brasiliense (1984).

BENSAÏD, D. Apresentação: uma crítica da emancipação política. In: MARX, K. Sobre a questão judaica. Trad: Nélio Schneider. São Paulo: Boitempo, 2010.

BIDET, J; KOUVELAKIS, S (ed). Critical Companion to Contemporary Marxism. Brill, 2008.

CALLINICOS, A. "Igualdade e capitalismo". In: BORÓN, A; AMADEO, J; GONZÁLEZ, S. (orgs.). A teoria marxista hoje: problemas e perspectivas. Buenos Aires: CLACSO, 2006, p. 253-269.

CHASIN, J. "A determinação ontonegativa da politicidade", Ensaios Ad Hominem/ Estudos e Edições Ad Hominem; $\mathrm{n}^{\circ}$ 1, tomo III, 2000.

COHEN, G. A. "Equality as fact and as norm: reflections on the (partial) demise of marxism." Lua Nova: Revista de Cultura e Política, $n^{\circ}$ 33, 1994, 123-134.

1986.

A. La teoría de la historia de Karl Marx: una defensa. Madrid: Pablo Iglesias, Siglo XXI de España,

COUTINHO, C.N. "Cidadania e modernidade." Perspectivas: Revista de Ciências Sociais 22.1, 1999.

GERAS, N. "The controversy about Marx and justice". New left review, v. 150, n. 3, p. 1, 1985.

HONNETH, A. "A textura da justiça Sobre os limites do procedimentalismo contemporâneo." Civitas-Revista de Ciências Sociais 9.3, 2009.

LOSURDO, D. "Como nasceu e como morreu o marxismo ocidental". Estudos sociológicos, Araraquara, v.16, n.30, p.213-242, 2011

LÖWY, M. A teoria da revolução no jovem Marx. Petrópolis: Vozes, 2002.

MACPHERSON, C.B. A teoria política do individualismo possessivo, de Hobbes até Locke. Paz e Terra, 1979.

MARX, K; ENGELS, F. A ideologia alemã. Boitempo Editorial, 2007.

Contribuição à crítica da economia política. 2.ed.- São Paulo: Expressão Popular, 2008.

Crítica da filosofia do direito de Hegel. Boitempo Editorial, 2005.

ENGELS, F. Manifesto comunista. Boitempo Editorial, 1998.

Manuscritos econômico-filosóficos. Boitempo Editorial, 2004.

Sobre a questão judaica. Trad: Nélio Schneider. São Paulo: Boitempo, 2010

REGO, WL; PINZANI, A, Vozes do Bolsa Família: autonomia, dinheiro e cidadania. São Paulo: Editora UNESP, 2013.

REYES MOREL, A. El socialismo normativo de G.A. Cohen: justicia como igualdad y comunidad. Universidad de Valencia, 2008

RYAN, A. "Justicia, Explotacion y el fin de la Moral". Revista de Ciencia Politica, vol. XII no 1-2, 1990. 45-65

SÁNCHEZ VÁZQUEZ, Adolfo. "Después del Derrumbe: Estar o no a la izquierda." Sistema. Revista de Ciencias Sociales, $\mathrm{n}^{\circ}$ 108, 1992, p. 57-67.

WOOD, A. "Justice and class interests". Philosophica no 33, 1984, p. 9-32.

Recebido em: 14/05/2014

Aprovado para publicação: 05/06/2014

\begin{tabular}{|c|c|l|l|l|l|}
\hline intuitio & $\begin{array}{c}\text { ISSN } \\
1983-4012\end{array}$ & Porto Alegre & Vol.7- $\mathrm{N}^{\mathrm{o}} .1$ & $\begin{array}{l}\text { Junho } \\
2014\end{array}$ & p.169-181 \\
\hline
\end{tabular}

